\title{
Analysis of Dynamical Behavior for Epidemic Disease COVID-19 with Application
}

\author{
Dr. Maysoon M. Aziz ${ }^{1} \quad$ Arqam S. Mahmood ${ }^{2}$ \\ aziz_maysoon@uomosul.edu.iq arqam.csp117@student.uomosul.edu.iq \\ Corresponding Author:
}

1.. Assist. prof. Department of Mathematics / College of Computer Sciences and Mathematics / University of Mosul, Mosul, Iraq

Email : [1] aziz_maysoon@yahoo.com

[2] asmd.2013mosl@gmail.com

Article History: Received:11 January 2021; Accepted: 27 February 2021; Published online: 5 April 2021

\begin{abstract}
In this paper, we will use the differential equations of the SIR model as a non-linear system, by using the Runge-Kutta numerical method to calculate simulated values for known epidemiological diseases related to the time series including the epidemic disease COVID-19, to obtain hypothetical results and compare them with the dailyreal statisticals of the disease for counties of the world and to know the behavior of this disease through mathematical applications, in terms of stability as well as chaos in many applied methods. The simulated data was obtained by using Matlab programms, and compared between real data and simulated datd were well compatible and with a degree of closeness. we took the data for Italy as an application. The results shows that this disease is unstable, dissipative and chaotic, and the Kcorr of it equal (0.9621), ,also the power spectrum system was used as an indicator to clarify the chaos of the disease, these proves that it is a spread,outbreaks,chaotic and epidemic disease .
\end{abstract}

Subject Area : Dynamical Systems

Keywords: Transformation of Runge-Kutta equations for SIR model, stabilization, chaotician, Results simulation.

\section{INTRODUCTION}

It is necessary to model the development of an infectious disease as a dynamic system with the study of its properties. the data necessary to construct a dynamic model are often available through biological considerations and time-series data for disease cases to fit and test the models [1], the qualitative behavior of systems of ordinary differential equations describing differential solutions for a long time has been studied, which is an important issue. one of the models that can be used to explain the characteristics of epidemiological diseases is the SIR model, which is a classical model that is susceptible to infection, which was built by (Kermack and Mckendrick) in 1927 and it has been designed extensively.Many expansions and extensions of this model have been used recently [2-3].

In this paper the equations of the SIR model have been used. It is a non-linear system using the numerical Runge-Kutta method of 4th order to simulate the hypothetical results of the epidemic disease that occupied the world COVID-19 and compare it with the real data given according to the statistics of the countries of the world for example we take data in Italy [4].

The degree of stability of the disease was also tested in several ways, all of which led to the result that it was unstable [5-9], and it chaos was tested by the binary test (0-1) and the result was that it was chaotic [10-13]. The Matlab program was used for the aforementioned operations to know in a time series that accompanied this disease, and we obtained the results, charts and drawings that prove the results of the solution for the theoretical side of studying this disease, also, the parameters and infected values (I) of the disease in the population were used in the power spectrum system of the SIR model and it give an indication that this disease is a chaotic [14$15]$.

\section{SIR MODEL}

The SIR model is a specialized mathematical model to study the behavior of epidemic diseases, where it calculate the theoretical number of people with an infectious disease in aclosed population is calculated over time, it's one of the simplest biological models and developed by Kermack-Mckendrick in 1927. The model is contain three non-linear ordinary differential equations related with a time-series as the following : 


\subsection{Description model}

$\left.\begin{array}{l}\frac{\mathrm{d} S}{d t}=-\beta S I \\ \frac{d \mathrm{I}}{d t}=\beta S I-\gamma \mathrm{I} \\ \frac{d R}{d t}=\gamma \mathrm{I}\end{array}\right\} \quad$ non-Linear System

$\mathrm{N}=\mathrm{S}+\mathrm{I}+\mathrm{R}, \mathrm{ds} / \mathrm{dt}+\mathrm{dI} / \mathrm{dt}+\mathrm{dR} / \mathrm{dt}=0$

Where :-

$\mathrm{N}$ : the total number of population .

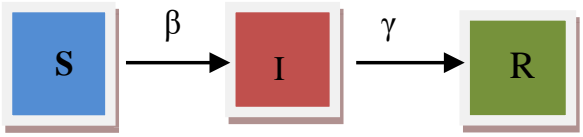

$\mathrm{S}(\mathrm{t})$ : is Susceptible people at time $(\mathrm{t})$.

$\mathrm{I}(\mathrm{t})$ : is Infected people at time $(\mathrm{t})$.

$\mathrm{R}(\mathrm{t})$ : is Removed people at time (t) (is contain recovered number and death number) .

$\beta:$ is a transmission rate. $\gamma:$ is recovered rate .

are constant parameters of the model

where : $\beta=\mu / \mathrm{S}, \gamma=1 / \mathrm{D} \quad \mu:$ is mortality rate in day, $\mathrm{D}:$ is duration of disease time .

the parameters $\left(\beta=10^{-5} \& \gamma=0.07\right)$ were calculated from the real data of daily statistics of

COVID-19 disease for Italy . and initial values of Italy $\left(S_{0}, I_{0}, R_{o}\right)=\left(3 \times 10^{6}, 3500,0\right)$.

The time series of real data of SIR model of COVID-19 for Italy showen in figure 1(A)

\section{BASIC REPRODUCTION NUMBER $\left(R_{0}\right):[2]$}

Definition : is represent to the average number of new infections generated by each infected person, The high value of $\left(R_{0}\right)$ mean easy to transmission the disease, and the low value of $\left(R_{0}\right)$ mean difficult to transmission the disease . $\left(R_{0}\right)$ is called threshold of disease, , the value of $\left(R_{0}\right)$ assumes that no pre-existign immunity, i.e it mean everyone is susceptible), where $\operatorname{Ro}=\beta S / \gamma$.

LEMMA : if $R_{0}>1$ then $\mathrm{I}(\mathrm{t})$ is increases and the disease is epidemic, and if $R_{0}<1$ then $\mathrm{I}(\mathrm{t})$ is dicreases and the disease is endemic .

Proof : from the SIR model we have $:-\mathrm{dI} / \mathrm{dt}=\beta \mathrm{SI}-\gamma \mathrm{I} \longrightarrow \mathrm{dI} / \mathrm{dt}=(\beta \mathrm{S}-\gamma) \mathrm{I} \longrightarrow \mathrm{dI} / \mathrm{I}=(\beta \mathrm{S}-\gamma) \mathrm{dt}$ by integral of two handsides : $\ln \mathrm{I}=(\beta \mathrm{SI}-\gamma \mathrm{I})+\mathrm{C}$

$\mathrm{I}(\mathrm{t})=\mathrm{e}^{\beta S \mathrm{~T}(\mathrm{t})-\gamma \mathrm{I}(\mathrm{t})} \cdot e^{C}$, when $\mathrm{t}=0 \longrightarrow \mathrm{I}(0)=e^{C} \longrightarrow$ then $\mathrm{I}(\mathrm{t})=\mathrm{e}^{\beta S T(\mathrm{t})-\gamma \mathrm{I}(\mathrm{t})} . \mathrm{I}(0)>0$.

when $\mathrm{dI} / \mathrm{dt}>0$ then $\beta$ SI $-\gamma \mathrm{I}>0$

$\beta \mathrm{SI}>\gamma \mathrm{I} \longrightarrow \beta \mathrm{S} / \gamma>1 \rightarrow R_{0}>1$.

\section{RUNGE-KUTTA 4th ORDER NUMERICAL METHOD :}

The Runge-Kutta numerical method of 4th order its one of the numerical classic method that it use to solve the ordinary differential equations for dynamic systems that are continuous nonlinear and time-bound with number of iterations to get the best approximation .

Description method :

$$
\begin{aligned}
& \mathrm{y}(\mathrm{n}+1)=\mathrm{y}(\mathrm{n})+\frac{\mathrm{h}}{6} *(\mathrm{k} 1+2 \mathrm{k} 2+2 \mathrm{k} 3+\mathrm{k} 4) \\
& \text { where }: \Delta \mathrm{t}=\mathrm{h}=t_{n+1}-t_{n} \text { and }: \\
& \mathrm{k} 1=\mathrm{f}(\mathrm{tn}, \mathrm{yn}) \\
& \mathrm{k} 2=\mathrm{f}\left(\mathrm{t}(\mathrm{n})+\frac{h}{2}, \mathrm{y}(\mathrm{n})+\mathrm{h} * \frac{k 1}{2}\right) \\
& \mathrm{k} 3=\mathrm{f}\left(\mathrm{tn}+\frac{h}{2}, \mathrm{yn}+\mathrm{h} * \frac{\mathrm{k} 2}{2}\right) \\
& \mathrm{k} 4=\mathrm{f}(\mathrm{tn}+\mathrm{h}, \mathrm{yn}+\mathrm{h} * \mathrm{k} 3)
\end{aligned}
$$

\section{TRANSFORMATION OF RUNGE-KUTTAEQUATIONS FOR SIR MODEL :}

From system (1) we have : $\mathrm{dS} / \mathrm{dt}=\mathrm{f} 1, \mathrm{dI} / \mathrm{dt}=\mathrm{f} 2, \mathrm{dR} / \mathrm{dt}=\mathrm{f} 3$.

( So , Io , Ro ) initial condition, to $=1$ and $(\beta, \gamma)$ consParameters

$\mathrm{K} 1=\mathrm{h} * \mathrm{f} 1$ (to, So, Io , Ro)

$\mathrm{L} 1=\mathrm{h} *$ f2(to , So, Io, Ro)

$\mathrm{M} 1=\mathrm{h} * \mathrm{f} 3$ (to , So, Io, Ro)

$\mathrm{K} 2=\mathrm{h}^{*}$ f1 $\left(\right.$ to $+\frac{h}{2}$, So $+\frac{K 1}{2}$, Io $\left.+\frac{L 1}{2}, \mathrm{Ro}+\frac{M 1}{2}\right)$ 


$$
\begin{aligned}
& \left.\mathrm{L} 2=\mathrm{h}^{*} \text { f2 (to }+\frac{h}{2} \text {, So }+\frac{K 1}{2}, \mathrm{Io}+\frac{L 1}{2}, \mathrm{Ro}+\frac{M 1}{2}\right) \\
& \left.\mathrm{M} 2=\mathrm{h} * \mathrm{f} 3 \text { (to }+\frac{h}{2}, \text { So }+\frac{K 1}{2}, \text { Io }+\frac{L 1}{2}, \mathrm{Ro}+\frac{M 1}{2}\right) \\
& \left.\mathrm{K} 3=\mathrm{h} * \mathrm{f} 1 \text { (to }+\frac{h}{2} \text {, So }+\frac{K 2}{2} \text {, Io }+\frac{L 2}{2}, \mathrm{Ro}+\frac{M 2}{2}\right) \\
& \mathrm{L} 3=\mathrm{h}^{*} \text { f2(to }+\frac{h}{2} \text {, So }+\frac{K 2}{2} \text {, Io }+\frac{L 2}{2}, \text { Ro }+\frac{M 2}{2} \text { ) } \\
& \left.\mathrm{M} 3=\mathrm{h} * \mathrm{f3} \text { (to }+\frac{h}{2} \text {, So }+\frac{K 2}{2} \text {, Io }+\frac{L 2}{2}, \text { Ro }+\frac{M 2}{2}\right) \\
& \mathrm{K} 4=\mathrm{h} * \mathrm{f} 1 \text { (to }+\mathrm{h} \text {, So }+\mathrm{K} 3 \text {, Io }+\mathrm{L} 3, \mathrm{Ro}+\mathrm{M} 3 \text { ) } \\
& \mathrm{L} 4=\mathrm{h} * \text { f2 (to }+\mathrm{h} \text {, So }+\mathrm{K} 3 \text {, Io }+\mathrm{L} 3, \mathrm{Ro}+\mathrm{M} 3 \text { ) } \\
& \mathrm{M} 4=\mathrm{h} * \mathrm{f} 3 \text { (to }+\mathrm{h}, \text { So }+\mathrm{K} 3 \text {, Io }+\mathrm{L} 3, \mathrm{Ro}+\mathrm{M} 3 \text { ) } \\
& S_{1}=\mathrm{So}+\mathrm{h} / 6 \times(\mathrm{K} 1+2 \mathrm{~K} 2+2 \mathrm{~K} 3+\mathrm{K} 4) \\
& I_{1}=\mathrm{Io}+\mathrm{h} / 6 \times(\mathrm{L} 1+2 \mathrm{~L} 2+2 \mathrm{~L} 3+\mathrm{L} 4) \\
& R_{1}=\mathrm{Ro}+\mathrm{h} / 6 \times(\mathrm{M} 1+2 \mathrm{M} 2+2 \mathrm{M} 3+\mathrm{M} 4)
\end{aligned}
$$

the process is repeated with (n) iterations by using Matlab program .

The time series of simulated data by Runge-Kutta of COVID-19 for Italy showen in figure 1(B) . from figure1(A) and (B) we notice that compatible and with a degree of closeness .

\section{STABILITY OF SIR MODEL}

Stability Analysis : there are many method to check the stability from it :

6.1 CHARACTERISTIC EQUATION ROOTS :

The Jacobian matrix of system (1) is :

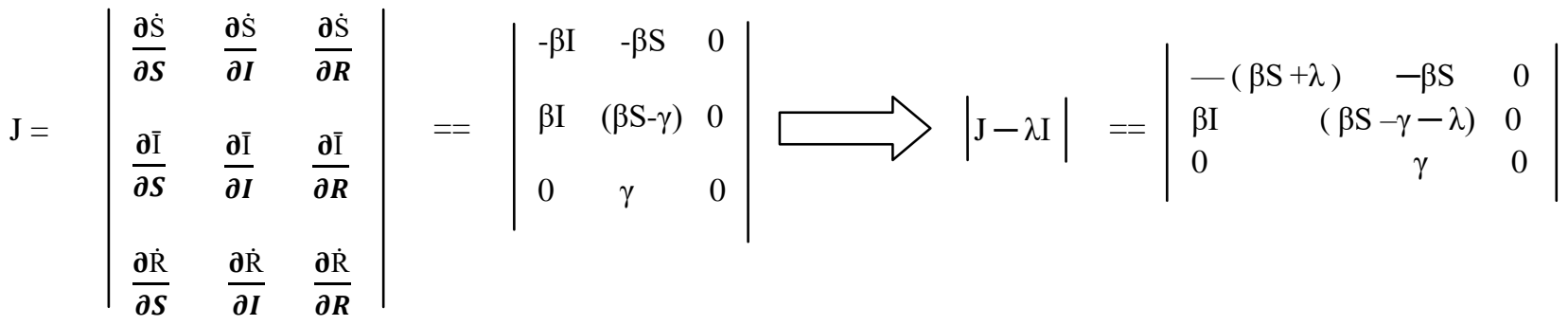

$\lambda^{3}+\beta I \lambda^{2}-\beta S \lambda^{2}+\gamma \lambda^{2}+\beta I \gamma \lambda=0$

$\lambda\left(\lambda^{2}+(\beta I-\beta S+\gamma) \lambda+\beta I \gamma\right)=0$

Intial values : $\left[S_{0}=3 \times 10^{6}, I_{0}=3500, R_{0}=0\right]$, Parameters : $(\beta=0.00001, \gamma=0.07)$

$\lambda_{1}=0$

$\lambda_{2}=29,8949(+\mathrm{ve})$

Since the values of $(\lambda)$ are positive then the system is unstable

$\lambda_{3}=0.0001(+\mathrm{ve})$

\subsection{ROUTH-HURWITZ STABILITY CRITERIAN}

\subsubsection{ROUTH STABILITY CRITERIA}

Routh table was established by English mathematician "Edward Routh" in 1876.

General layout for Routh table :

\begin{tabular}{l|ll} 
Sn & an an-2 & an-4 $\ldots \ldots \ldots .$. \\
Sn-1 an-1 an-3 & an-5 $\ldots \ldots \ldots \ldots$
\end{tabular} 


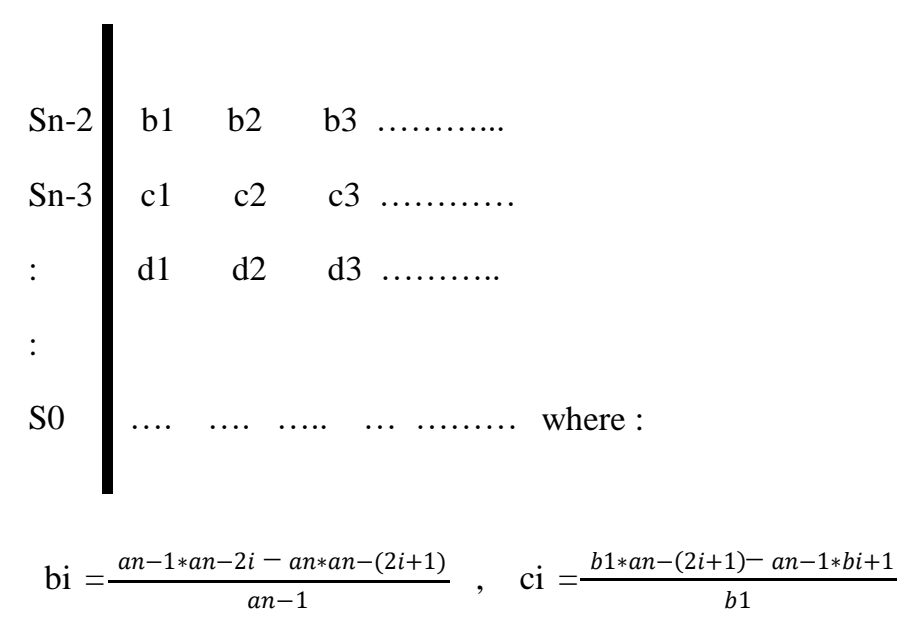

6.2.1.1 THEOREM : If the signals change in the first column in Routh-table then the system is unstable.

PROOF: by characteristic equation (2): $\lambda^{3}+(\beta I-\beta S+\gamma) \lambda^{2}+\beta I \gamma \lambda=0$

where : $\quad \mathrm{a} 3=1, \mathrm{a} 2=(\beta \mathrm{I}-\beta \mathrm{S}+\gamma), \mathrm{a} 1=\beta \mathrm{I} \gamma$, ao $=0$

$\mathrm{b} 1=\frac{a 2 \times a 1-a 3 \times a o}{a 2}=\mathrm{a} 1-\frac{a 3 \times a o}{a 2}=\beta \mathrm{I} \gamma-\frac{1 \times 0}{\beta I-\beta S+\gamma}=\beta \mathrm{I} \gamma>0$

$\mathrm{b} 2=\frac{a 1 \times a 4-a 5 \times a o}{a 1}=\frac{0-0}{\beta I \gamma}=0, \mathrm{c} 1=\frac{b 1 \times a o-a 2 \times b 2}{b 1}=0$

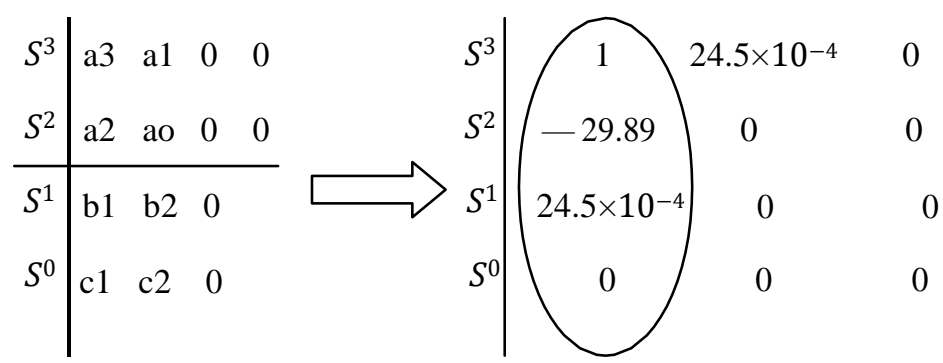

Since there is a negative element in the first column of the Routh-Table then the system is unstable .

\subsubsection{HURWITZ STABILITY CRITERIA}

Hurwitz Matrix :

$$
\mathrm{H}=\left|\begin{array}{ccccccc}
\mathrm{a} 1 & \mathrm{a} 3 & \mathrm{a} 5 & \ldots .0 & 0 & 0 \\
\mathrm{a} 0 & \mathrm{a} 2 & \mathrm{a} 4 & \ldots .0 & : & : \\
0 & \mathrm{a} 1 & \mathrm{a} 3 & \ldots .0 & : & : \\
0 & \mathrm{a} 0 & \mathrm{a} 2 & \ldots .0 & 0 & : \\
: & 0 & \mathrm{a} 1 & \ldots . \mathrm{a}_{\mathrm{n}} & : & \\
: & : & \mathrm{a} 0 & \ldots . \mathrm{a}_{\mathrm{n}-1} & 0 & : \\
: & : & & \ldots & & \\
: & : & 0 & \ldots . \mathrm{a}_{\mathrm{n}-2} & \mathrm{a}_{\mathrm{n}} & \\
: & : & & \ldots . \mathrm{a}_{\mathrm{n}-3} & \mathrm{a}_{\mathrm{n}-1} & : \\
0 & 0 & 0 & \ldots . \mathrm{a}_{\mathrm{n}-4} & \mathrm{a}_{\mathrm{n}-2} & \mathrm{a}_{\mathrm{n}}
\end{array}\right|
$$


It was established by German mathematician "Adolf Hurwitz” in 1895 that a real polynomial (P)

$\Delta 1(\mathrm{p})=|\mathrm{a} 1|=>0, \Delta 2(\mathrm{p})=\left|\begin{array}{ll}\mathrm{a} 1 & \mathrm{a} 3 \\ \mathrm{a} 0 & \mathrm{a} 2\end{array}\right|=>0, \Delta 3(\mathrm{p})=\left|\begin{array}{ccc}\mathrm{a} 1 & \mathrm{a} 3 & \mathrm{a} 5 \\ \mathrm{ao} & \mathrm{a} 2 & \mathrm{a} 4 \\ 0 & \mathrm{a} 1 & \mathrm{a} 3\end{array}\right|=>0$

$\Delta \mathrm{k}(\mathrm{p}):$ are called the Hurwitz determinants .

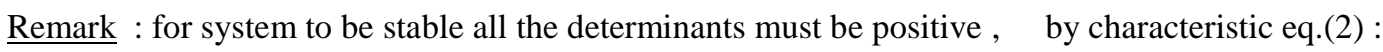

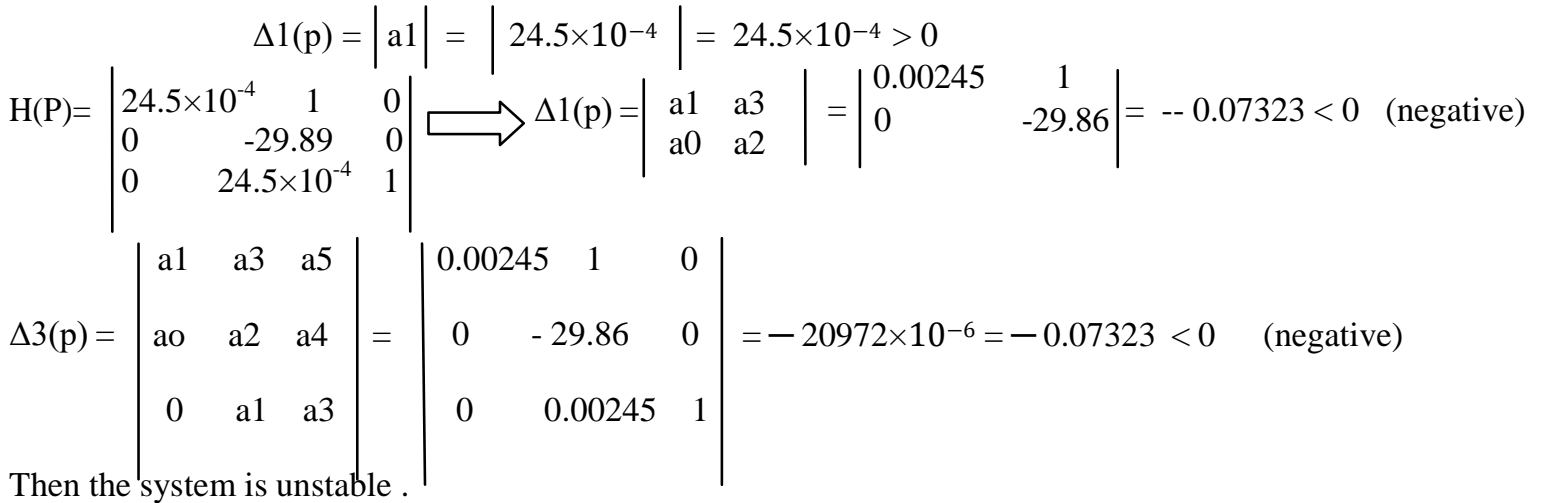

\section{3 LYAPUNOV FUNCTION :}

$\mathrm{V}(\mathrm{S}, \mathrm{I}, \mathrm{R})=\frac{1}{2}\left(S^{2}+I^{2}+R^{2}\right)$

$\frac{d v}{d t}=\mathrm{V}(\mathrm{S}(\mathrm{t}), \mathrm{I}(\mathrm{t}), \mathrm{R}(\mathrm{t}))=\mathrm{S} \dot{\mathrm{S}}+\mathrm{II}+\mathrm{R} \dot{\mathrm{R}}$

$\mathrm{V}=\mathrm{S} \times(-\beta \mathrm{I} \gamma)+\mathrm{I} \times(\beta \mathrm{SI}-\gamma \mathrm{I})+\mathrm{R} \times(\gamma \mathrm{I})$

By initial values and parameters we obtain on :

$\mathrm{V}=\quad>0$ ( positive) Then the system is unstable.

\section{DISSIPATIVITY :}

By jacobian of SIR system we will know if the system is dissipative or not

$\mathrm{J}=\left|\begin{array}{cc}-\beta \mathrm{I} & -\beta \mathrm{S} \\ \beta \mathrm{I} & \beta \mathrm{S}-\gamma\end{array}\right|=(-\beta \mathrm{I})(\beta \mathrm{S}-\gamma)-(-\beta \mathrm{S})(\beta \mathrm{I})=-\beta \mathrm{H} \beta \mathrm{S}+\beta \mathrm{I} \gamma+\beta \mathrm{I} \beta \mathrm{S}=\beta \mathrm{I} \gamma$

By initial values and parameters we obtain on :

$|\mathrm{J}|=0.00245<1 \quad$ then the system is dissipative .

\section{CHAOTIC ANALYSIS :}

To explain the chaotic state we will take the (0-1) test to know if the system is regular or chaotic .

\subsection{BINARY (0-1) TEST :}

Consider scalar observable $(\mathrm{k}): \mathrm{Pn}=\sum_{k=1} \phi(k) \cos (k c) \quad, \quad \mathrm{qn}=\sum_{k=1} \phi(k) \sin (k c)$ 
Where $c \in(0, \pi), \mathrm{n}=1,2,3, \ldots \ldots, \mathrm{L}$ from behavior of Pn and qn can be computing the Mean Square Displacenemt $(\mathrm{MSD})=\mathrm{M}(\mathrm{n})$

$$
\mathrm{M}(\mathrm{n})=\lim _{L \rightarrow \infty}\left(\frac{1}{L}\right) \mathrm{Z}_{k=1}\left[(P(k+n)-P(k))^{2}+(q n(k+n)-q n(k))^{2}\right]
$$

Where $\mathrm{n}=1,2, \ldots \mathrm{L} / 10$.

$$
\operatorname{Vosc}(\mathrm{n})=[\mathrm{E}(\boldsymbol{\phi})]^{2} \times \frac{1-\cos (n c)}{1-\cos (c)},, \quad \text { where } \mathrm{E}(\boldsymbol{\phi})=\lim _{L \rightarrow \infty}\left(\begin{array}{c}
1 \\
L
\end{array}\right) \underset{k=1}{\sum_{k}} \phi(k)
$$

Then $D(n)=M(n)-\operatorname{Vosc}(n)$.

$\mathrm{K} \operatorname{corr}=\mathrm{Kc}=\lim _{n \rightarrow \infty} \frac{\log M c(n)}{\log (n)}$.

\section{$\underline{\text { Kc states : }}$}

Either the value of $\mathrm{K} \cong 0$ it is signifying to regular dynamics

Or the value of $K \cong 1$ it is signifying to chaotic dynamics . where $K c \in[0,1]$.

By using Matlab program we get : $\quad$ Kc $=$ Kcorr $=0.9621 \cong 1$

$\mathrm{Kc}=0.9621 \cong \mathbf{1}$ Italy

Then the system is chaotic . ( in Italy ).

Remark: if the motion is torus then the dynamic system is regular (non-chaotic), and if it behavior like a Brownian motion then the dynamic system is said it chaotic .

shows the chaotic of real data for Italy by using Zero-one test showen in figure2(A), and the chaotic of simulated data for Italy byusing Zero-one test showen in figuer2(B) .

\section{THE POWER SPECTRUM : [14-15]}

We investigate the nature of the power spectral density computed numerically $\mathrm{P}(\mathrm{f}, \mathrm{N}, \mathrm{T})$ for the time series extracted form a continous dynamic system . We highlight now $\mathrm{P}(\mathrm{f}, \mathrm{N}, \mathrm{T})$ differs form the real power spectrum of general random process .A non-zero $\mathrm{T}$ value results in a liasing. Whose $\mathrm{P}(\mathrm{f}, \mathrm{N}, \mathrm{T})$ decays at higher frequencies as $[\pi \mathrm{T} / \sin \pi \mathrm{Tf}]^{2}$ which is a form borrowed form $1 / \mathrm{f}^{2}$. [Where P:is the power spectrum system ].

The model displays quasi-temporal and spatial fluctions overawide range of time scales with the form $\left(1 / \mathrm{f}^{\mathrm{a}}\right)$ power spectrum and the results of expantion behaviour of this disease prevalence are discussed.

We have become accustomed to considering the epidemic as agreat fluctuation away from the average level of endemic disease in ahomogeneous host society, the sudden increase in the status of notifications and the number of infected people is the result of a sudden increase in population density or the effectof the strength of the disease or failure to take the necessary precautions and measures to limit the spread of this epidemic, which reinforces reproductive capacity of related disease. The presence of wide spread fluctuations in the simple SIR model provides us with a different view of disease in susceptible population were the viral colonies in the each infected person are subject to biological laws determined by the immune system of the infected host and this determines epidemiological parameters such as incubation period and infection period, however the presence of measure or indicator of fluctuation indicates that from this viral activity a comprehensive dynamic appears that ensures the continuation of the disease and the speed of its spread . the time series of infection may not show any specific structure but the $S$ (f) power spectrum appears in reference to fluctuations over wide range of time scales discrete for simulation .

The strongest feature of chaotic dynamics data is the absence of periodicity and the time series is said to be precisely cycle if it is $\mathrm{x}(\mathrm{t})=\mathrm{x}(\mathrm{t}+\mathrm{h}), \forall \mathrm{t}$. This means that the duration of the cycle remains unchanged. The spectroscopy is a good indicator of the behavior of time series. That is if the behavior is chaotic then the values do not appear and interfere with the higher individual as is the case in cyclical behavior. The figure (4) shows the estimated function of the observed power spectrum for the number of infectedes during the time period by using the following :-

$\mathrm{f}(\mathrm{w})=\frac{1+2 \sum_{k=1}^{N} \cos (k w p)}{2 \pi}, \quad$ Where $: \mathrm{wp}=\frac{2 \pi P}{T}, \quad \mathrm{P}=1,2, \ldots \ldots \cdot \frac{T}{2}, \mathrm{~W} \in[0,2 \pi]$ and $\mathrm{p}=[2 \sqrt{T}]$.

The Power Spectrum Of real and simulated data of Italy an indicator to clarify the chaos of the disease showen in figure (4) . 
10. SHAPES :

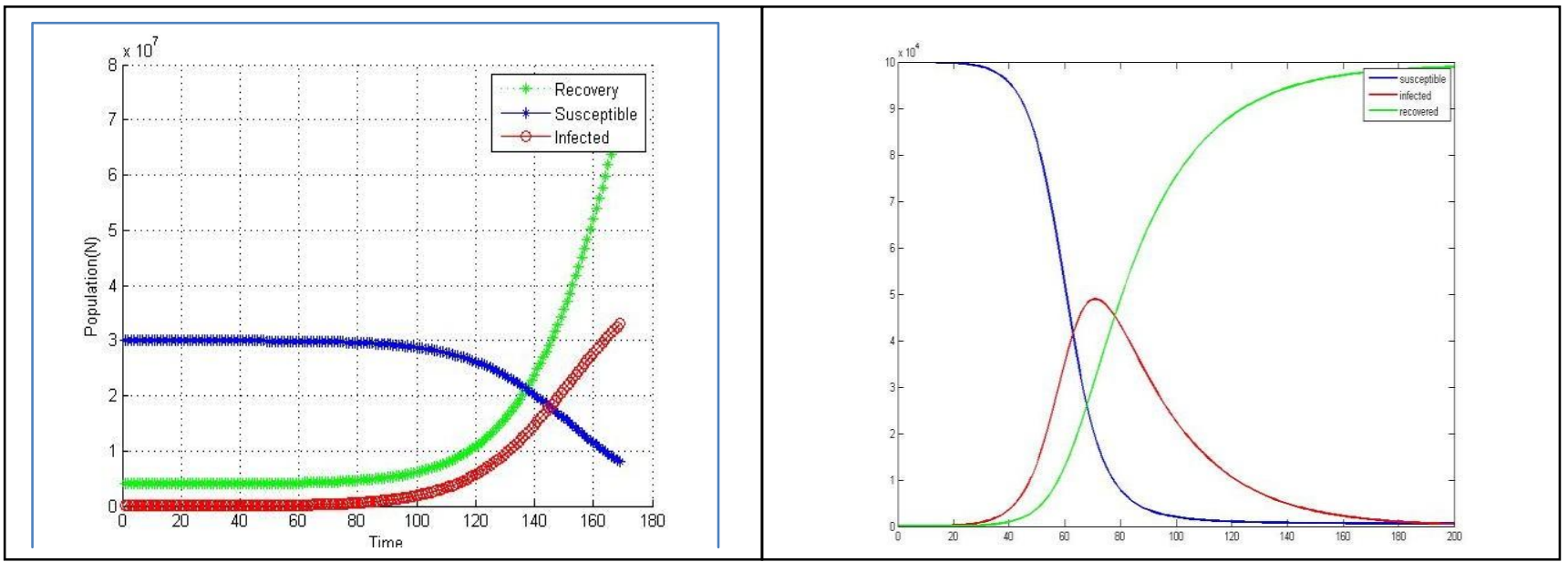

Figure 1(A) : show simulated data of susceptible, infected and recovered of disease

Figure1 (B) :show susceptible,infected and recovered of disease in SIR model

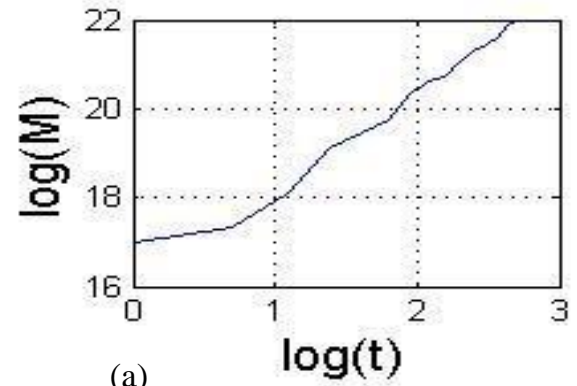

kcorr2

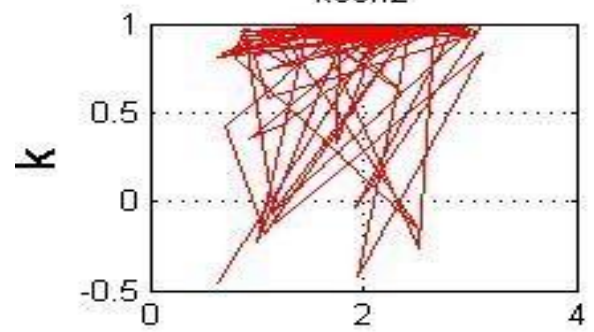

(c)

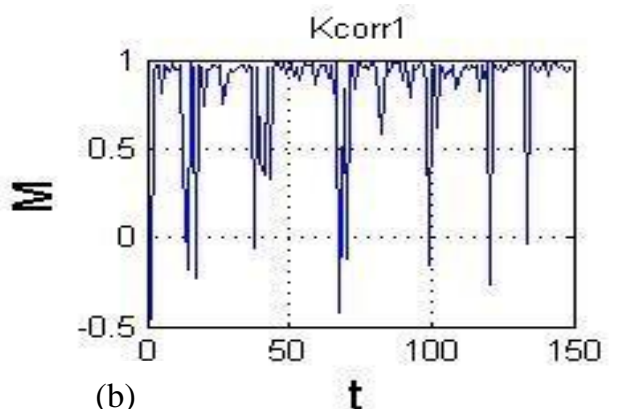

(b)

Asymptotic growth rate $\mathrm{K}$ versus

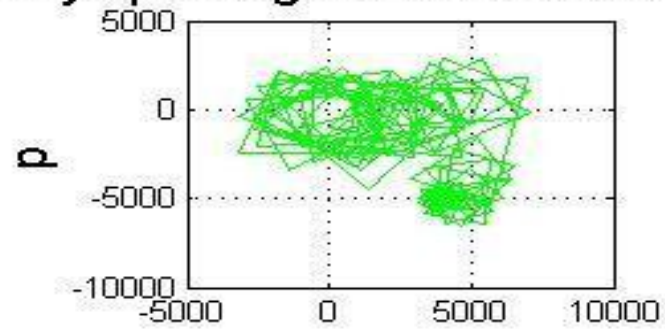

(d)

q

Figure 2(A) :show the chaotic of real data for Italy by Zero-one test $(a): \log (M)$ verses $(b)$ : $M$ verses $t(c): k$ verses $c(d): p$ verses $q$ 


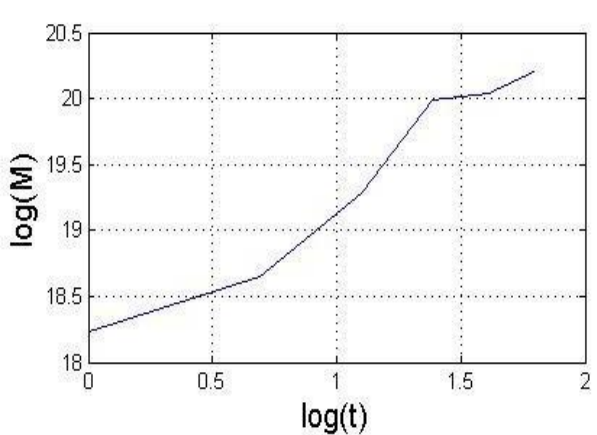

(a)

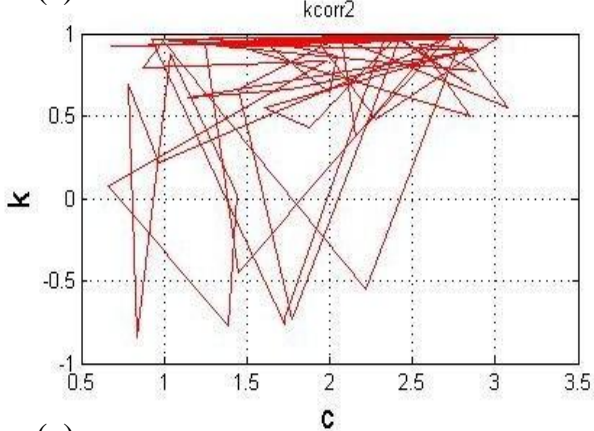

(c)

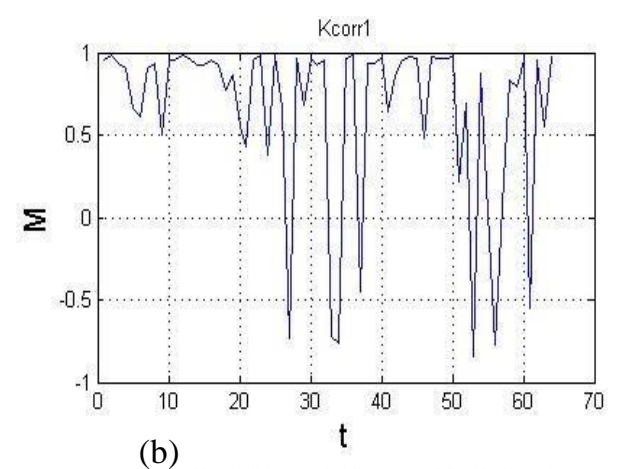

(b)

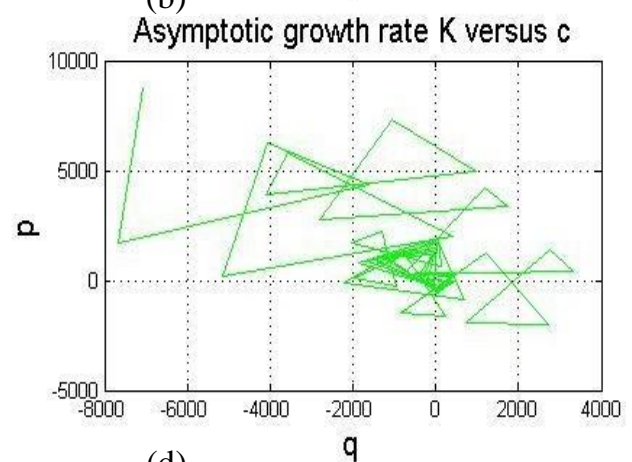

(d)

Figure 2(B): show the chaotic of simulated data for Italy by Zero-one test (a): $\log (M)$ verses $\log (t),(b): M$ verses $t,(c): k$ verses $c,(d): p$ verses $q$

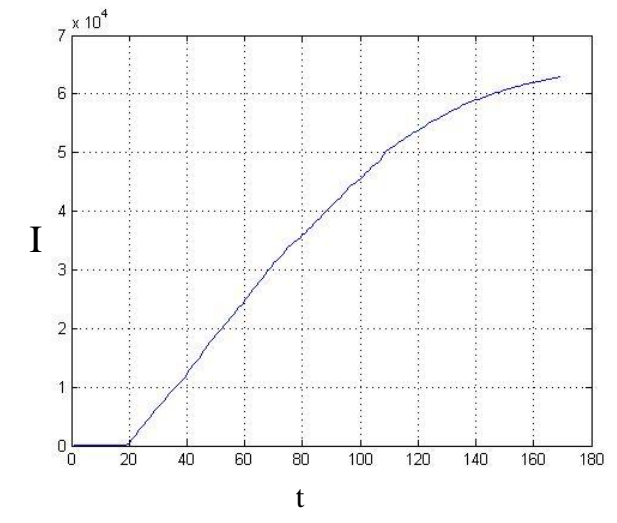

Fig(a): real data of infection for

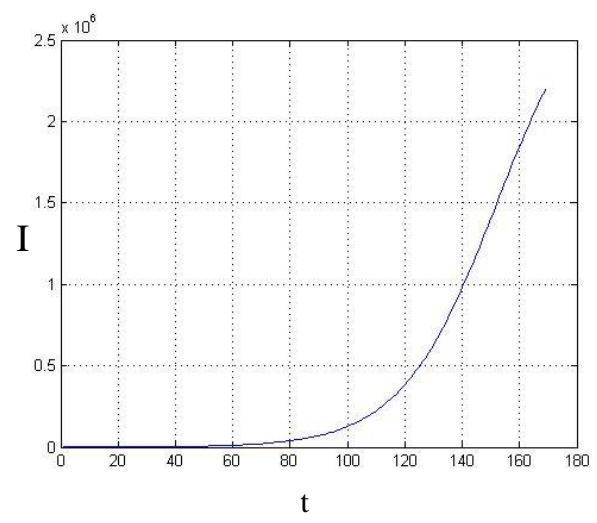

Fig(b): simulated data of infection for

Figure 3 


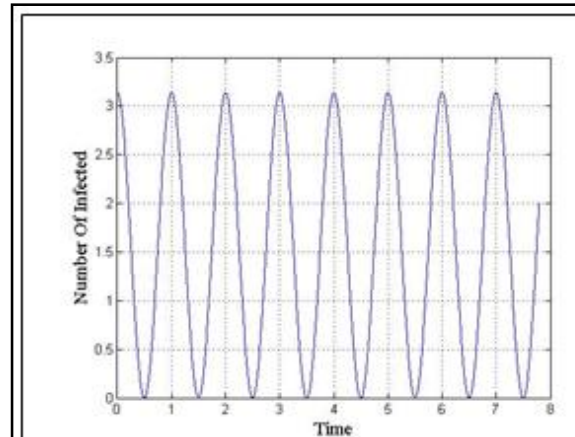

(a) :Real data : number Of infection verses time

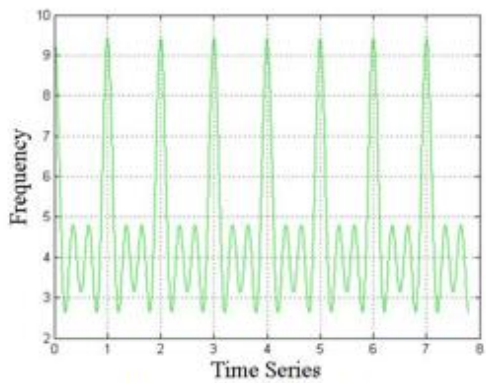

(c):Real data : frequency verses time series

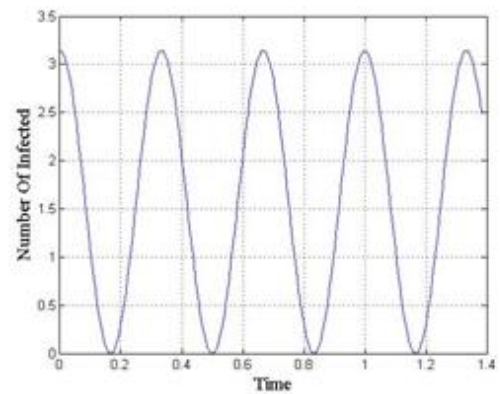

(b) :Simulte dat: number Of infection verses time

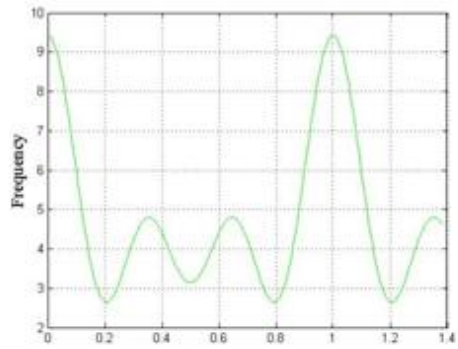

(d) : Simulte Data : frequency verses time

Figure 4 : show Power Spectrum Of Italy

\section{CONCLUSION :}

In this paper the SIR model was defined and the Runge-Kutta numerical method defined, and we transformed the method with the model and used this transformation to solve non-linear problems related to the time series in which time akey factor to determine its behavior and nature and obtain simulated results after giving initial values for the epidemic disease COVID-19. We proved in Lemma that $\mathrm{dI} / \mathrm{dt}>0$ and through that it we proved that Ro>1 and that mean the disease is epidemic. So we have real data obtained through the daily statistics for the countries of the world and the simulated data resulting from the application of the conversion . The real and the simulated data were tested in terms of stability in several mathematical method including the characteristics ,Routh-Hurwitz criteria and Lyapunov function and it appeared to be unstable. we applied the law of dissipativity on it and we got that it dissipative, $(|\mathrm{J}|=0.0049<1)$. The Binary test $(0-1)$ was also used to examine its chaotion, it was found that it was chaotic, as the value of Kcorr was nearly to one . (Korr=0.9621) , also the power spectrum system was used as an indicator to clarify the chaos of the disease

.The Matlab program has been used in all the aforementioned processes to obtain the results and the figures that illustrate this are attached to each stage of the work. We have dealt with the statistical data of Italy as an example of the application of what was in this country of dynamics and a strong impact of the disease on the population during the period of time, and that a large part of them were exposed to this disease which is spreading in a large and rapid manner .

\section{ACKNOWLEDGEMENTS}

The authors are very grateful to the University of Mosul / College of Computer Sciences and Mathematics for their provided facilities, which helped to improve the quality of this work.

\section{REFERENCES}

[1] Herbert W. Hethcote, The basic epidemiology models: models , expression for R0, parameter estimation , and applications. MATHEMATICAL UNDERSTANDING OF INFECTIOUS DISEASE DYNAMICS, World Scientific Publishing Co. Pte. Ltd, vol.61

[2] Howard (Howie) Weiss, The SIR model and the Foundations of Public Health ,MATerials MATemàtics ,Volum 2013, treball no. 3, 17 pp.

[3] Dilip Kumar Bagal, Arati Rath, Abhishek Barua, and Dulu Patnaik ,Estimating the parameters of susceptibleinfected-recovered model of COVID-19 cases in India during lockdown periods, Chaos, Solitons \& Fractals, ELSEVIER, vol. 34, November 2020 
[4] Md. Tareque Hossaina, Md. Musa Miahb, Md. Babul Hossainc, Numerical study of Kermack-Mckendrik SIR model to predict the outbreak of Ebola virus diseases using Euler and fourth order Runge-Kutta methods, American Scientific Research Journal for Engineering, Technology, and Sciences (ASRJETS), Volume 37, No 1, pp 1-21, 2017

[5] ECE 680 Modern Automatic Control, Routh's Stability Criterion ,vol. 6, June 13, 2007.

[6] Dr.Maysoon M. Aziz, Dalya M. Merie, Stability and chaos with mathematical control of 4-d dynamical system, Indonesian Journal of Electrical Engineering and Computer Science, Vol. 20, No. 3, December 2020, pp. 1242 1251

[7] Korobeinikov, Andrei, LYAPUNOV functions and global stability for SIR and SIRS epidemiological models with non-linear transmission, Hokkaido University Collection of Scholarly and Academic Papers : HUSCAP, Bulletin of Mathematical Biology, 68(3), 615-626

[8] The (0-1) test for chaos : A review, present by (Georg A. Gottwald and Ian Melbourne),, abstract Georg A. Gottwald ,school of mathematics \& statistics,, the university of Sydney; 2006 Sydney NSW, Australia.

[9] Loukas Zachilas and Iacovos N. Psarianos, Examining the chaotic behavior in dynamical systems by means of the (01) test, Hindawi Publishing Corporation Journal of Applied Mathematics,vol. 14, 2012

[10]R. Gopal, A. Venkatesan, and M. Lakshmanan, Applicability of (0-1) test for strange nonchaotic attractors , AIP Publishing, Vol. 16,2013 .

[11] Dr.Maysoon Aziz, Muhammad Hamid, The Possibility of Increasing The Predictability Indices After Control of 3DContinuous-Time System, International Conference on Computing and Information Science and Technology and Their Applications (ICCISTA), Vol. 5, September 2019

[12]Dr. Maysoon M. Aziz, Mansour N. faraj, Numerical and Chaotic Analysis of CHUA'S CIRCUIT, Journal of Emerging Trends in Computing and Information Sciences, Vol. 9, NO. 5, May 2012

[13]R. Gopal, A. Venkatesan, and M. Lakshmanan, Applicability of 0-1 test for strange nonchaotic attractors , AIP Publishing ,Vol. 16, 5 June 2013.

[14] R.M. Anderson and C. J. Rhodes, Dynamics in a lattice epidemic model, Physics Letters A 210 (1996) 183-188, vol.6.

[15]Dr. Maysoon M. Aziz, Mansour N. Faraj, Diffculty of predicting earthquakes in MOSUL dam , International Journal of Technical Research and Applications, Volume 3, Issue 6 (November-December, 2015), PP. 29-36. 